\title{
A gestão democrática nos sistemas de ensino: a experiência das Conferências Municipais de Educação e da Rede de Colaboração Tocantins no século XXI
}

\footnotetext{
Greice Quele Mesquita Almeida ${ }^{1}$, (D) Leonardo Victor dos Santos ${ }^{2}$, (iD) Alberto Damasceno ${ }^{3}$

${ }^{1}$ Instituto Federal do Tocantins - IFTO. Licenciatura em Computação. Campus Dianópolis. Rodovia To-040, Km 349, Loteamento Rio Palmeira, Lote 01, Zona Rural. Dianópolis - TO. Brasil. ${ }^{2}$ Universidade Federal do Tocantins - UFT.

${ }^{3}$ Universidade Federal do Pará - UFPA.

Autor para correspondência/Author for correspondence: greice.almeida@ifto.edu.br
}

\begin{abstract}
RESUMO. Os municípios brasileiros, e em particular os do Tocantins, estão em processo de planejamento, organização e realização das Conferências Municipais de Educação neste segundo semestre de 2021. O objetivo deste artigo é compreender as Conferências Municipais de Educação como elemento do Sistema Municipal de Educação e como espaço de materialização do princípio da gestão democrática da educação, tendo o Plano Municipal de Educação como referência e foco. Tomando por base fontes documentais e bibliográficas, este trabalho destaca que o processo de realização das conferências pode servir de mecanismo e espaço de resistência, reivindicatórios, propositivos e avaliadores das políticas públicas educacionais, favorecendo a autonomia das redes e sistemas municipais em contraposição ao esvaziamento e desmonte da educação pública pelo governo federal.
\end{abstract}

Palavras-chave: conferências municipais de educação, sistema municipal de educação, plano municipal de educação, gestão da educação municipal, rede colaboração tocantins. 


\title{
Democratic management in education systems: the experience of municipal education Conferences and the Tocantins collaboration network in the $21^{\text {st }}$ century
}

\begin{abstract}
Brazilian municipalities, particularly in Tocantins state, are amidst the planning, organization and execution of the Municipal Education Conferences this second semester of 2021. This paper aims to understand the Municipal Education Conferences as an element within the Municipal Education System and as a space to make real the principle of democratic management in education, having the Municipal Education Plan as a reference and a focus. Sourcing from bibliographical and documental, this study highlights that the process of making the conferences may serve as mechanism and space of resistance, assertive, propositive and assessive of public educational policies, favoring the autonomy of municipal networks and systems as opposed to the dismantling and depletion of public education by the federal government.
\end{abstract}

Keywords: municipal education conferences, municipal education system, municipal education plan, management of municipal education, tocantins collaboration network. 


\section{Gestión democrática en sistemas educativos: la experiencia de las Conferencias Municipales de Educación y la Red de Colaboración de Tocantins en el siglo XXI}

RESUMEN. Los municipios brasileños, y en particular los de Tocantins, están en proceso de planificación, organización y realización de Conferencias Municipales de Educación en el segundo semestre de 2021. El objetivo de este artículo es entender las Conferencias Municipales de Educación como un elemento del Sistema Municipal de Educación y como espacio para materializar el principio de gestión democrática de la educación, con el Plan Municipal de Educación como referente y enfoque. A partir de fuentes documentales y bibliográficas, este trabajo destaca que el proceso de realización de conferencias puede servir como mecanismo y espacio de resistencia, reclamos, propuestas y evaluadores de políticas públicas educativas, favoreciendo la autonomía de las redes y sistemas municipales frente al vaciamiento y desmantelamiento de educación pública por parte del gobierno federal.

Palabras clave: congresos municipales de educación, sistema educativo municipal, plan de educación municipal, gestión de la educación municipal, red de colaboración de tocantins. 


\section{Introdução}

No Brasil, a partir da década de 1980, foram realizadas seis Conferências Brasileiras de Educação (CBE) e foram realizados cinco Congressos Nacionais de Educação (Coneds), entre 1996 e 2004. Além disso, a Câmara dos Deputados, por meio de sua Comissão de Educação e Cultura, realizou cinco Conferências Nacionais da Educação de 2000 a 2005, em 2006, ocorreu a Conferência Nacional de Educação Profissional Tecnológica; em 2008, a Conferência Nacional de Educação Básica e, em 2009 a Conferência Nacional de Educação Escolar Indígena.

A partir de 2010, foram retomadas as Conferências Nacionais de Educação (Conae), gerando Conferências Municipais, Intermunicipais e Estaduais de Educação em 2009, 2013 e a própria Conae de 2010, 2014 e 2018, tivemos também a Conferência Nacional Popular de Educação (Conape), em 2018, organizada pelo Fórum Nacional Popular de Educação com vistas à avaliação e novas proposições de políticas públicas educacionais.

Considerando esse cenário, o objetivo deste artigo é compreender as Conferências Municipais de Educação realizadas a partir da década de 1980, como elemento do Sistema Municipal de
Educação e como espaço de materialização do princípio da gestão democrática da educação, tendo o Plano Municipal de Educação como referência e foco. Tomando por base fontes documentais como a Lei de Diretrizes e Bases da Educação Nacional (LDB), o Plano Nacional de Educação (PNE), o Plano Estadual de Educação do Tocantins (PEETO), os documentos da Conferência Nacional de Educação (Conae), da Conferência Nacional Popular de Educação (Conape), em documentos da Rede ColaborAção Tocantins e bibliográficas, este trabalho destaca que o processo de realização das conferências pode servir de mecanismos e espaços de resistência, reivindicatórios, propositivos e avaliadores das políticas públicas educacionais, favorecendo a autonomia das redes e sistemas municipais, em contraposição ao esvaziamento e desmonte da educação pública em curso pelo governo federal e promovendo a difusão da compreensão da gestão democrática.

O país, a partir do Plano Nacional de Educação de 2014, passou a contar com a disposição legal das conferências educacionais como um dos elementos dos sistemas de educação e ensino, que determinou que elas deveriam ser realizadas em âmbito nacional, sob a 
responsabilidade da União, e nas demais esferas do Poder Público.

No segundo semestre de 2021, os municípios brasileiros, e em particular do Tocantins, estão em processo de planejamento, organização e realização das Conferências Municipais de Educação, cujos processos são objeto desse trabalho.

Nesse sentido, para o desenvolvimento desta discussão, nosso caminho metodológico considera os aspectos instrumentais e a discussão teórica, concentrando em uma abordagem qualitativa e na construção dos dados e informações por meio de pesquisa bibliográfica e documental (Creswell, 2010).

A respeito da organização textual, o artigo está organizado em duas seções, além desta introdução e das considerações finais, que abordam elementos históricos das conferências de educação realizadas nos anos 2000, as conferências municipais de educação, questões teóricas e legais e a(s) possibilidade(s) das conferências de educação se constituírem como um elemento do Sistema Municipal de Ensino/Educação e instrumento da gestão democrática.

Conferências de Educação dos anos 2000: uma história de conquistas e rupturas
O Governo Federal institucionalizou as Conae em atendimento a demandas de educadores/entidades desde os anos de 1980, que vinham promovendo e organizando eventos dessa natureza por meio de entidades da sociedade civil. Essas conferências são, portanto, “... fruto de uma longa trajetória de conferências constituídas por diversos movimentos sociais e, nesta chave, pode ser considerada uma conquista dos movimentos sociais ligados à área de educação" (Gouveia, 2010, p. 1). Entretanto, pode haver controvérsias.

A I Conferência Nacional da Educação, realizada no período de 28 de março a 1 de abril de 2010, em Brasília, no Distrito Federal, teve como tema "Construindo o Sistema Nacional Articulado de Educação: o Plano Nacional de Educação, Diretrizes e Estratégias de Ação" e foi precedida de conferências municipais, intermunicipais e estaduais realizadas durante o ano de 2009, contando com intensa participação da sociedade civil, de agentes públicos, entidades de classe, estudantes, profissionais da Educação, pais e estudantes. Ao todo, foram credenciados 3.889 participantes, sendo 2.416 delegados e 1.473 entre observadores, palestrantes, imprensa e membros de equipes da coordenação, apoio e cultura (Brasil, 2011a). 
O documento final da Conae (Conae, 2010, p. 12) caracterizou a Conferência como espaço de mobilização e participação democrática e observou que o evento se constituiu

num espaço democrático de construção de acordos entre atores sociais, que, expressando valores e posições diferenciadas sobre os aspectos culturais, políticos, econômicos, apontam renovadas perspectivas para a organização da educação nacional e para a formulação do Plano Nacional de Educação 2011-2020.

Gouveia (2010, p. 4) afirma que a novidade na realização da Conae "foi que o governo federal compôs a comissão organizadora e subsidiou financeiramente a realização da conferência. O que, se não lhe confere a condição de uma conferência do governo, representa um reconhecimento institucional dessa forma de decidir as políticas públicas".

A Conae 2010 foi organizada seguindo as orientações de um Regimento Interno elaborado pela Comissão Organizadora Nacional, função atribuída pela Portaria Normativa $\mathrm{n}^{0} 10$, de 3 setembro de 2008, que instituiu como seria composta essa comissão, estabelecendo, também, orientações iniciais para a realização de conferências, em 2009, em etapas municipais, estaduais e distritais. A Comissão Organizadora da Conae teve representantes de 34 entidades diferentes, contando com membros titulares e suplentes (Conae, 2010).

O coordenador-geral da Comissão Organizadora, Francisco das Chagas, em entrevista concedida à revista Educação \& Sociedade, destacava que o primeiro acordo necessário para que o evento fosse realizado foi organizar uma comissão plural que representasse a sociedade civil organizada (2010, p. 1034):

O grande e primeiro acordo para que a conferência acontecesse foi organizar a comissão, fazer com que a comissão organizadora acontecesse de fato. Esse foi o primeiro grande movimento. Não foi tão difícil porque nós já tínhamos a experiência da organização da CONEB, mas esse foi o primeiro desafio.

Para o coordenador geral os motivos que levaram a Comissão Organizadora a articular a Conae com a formulação do novo PNE, ou seja, aprovar diretrizes para o Sistema Nacional de Educação e, nessas diretrizes, aprovar também outras para o PNE se balizaram na preocupação de

não fazer com que a discussão da conferência fosse apenas o PNE, porque, se não, nós não poderíamos discutir o sistema, a concepção do sistema, etc. Então, nós tivemos esse cuidado, nós aqui talvez tenhamos a consciência de que o PNE, como é muito mais imediato, uma vez que o atual está terminando, com certeza é um tema muito forte. Nós podíamos ter feito uma conferência e o tema da conferência ser: Plano Nacional de Educação. Pronto. Mas nós não 
queríamos, nós trabalhamos para que não fosse assim. Terminou que 0 plano ganhou realmente uma dimensão maior, mas nós tivemos sempre o cuidado de dizer que a conferência não ia aprovar um Plano Nacional de Educação, a conferência ia aprovar diretrizes para o sistema nacional e, dentro dessas diretrizes, ia aprovar também diretrizes para o Plano Nacional de Educação. Em alguns casos, a conferência aprovou até metas para o plano; isso é importante inclusive (Chagas, 2010, p. 1037).

Isso reitera a tese de Saviani (1999), de que existe estreita relação entre sistema de ensino e plano de educação, uma vez que o sistema é a unidade de vários elementos intencionalmente reunidos, de modo a formar um conjunto coerente e operante, o plano configura-se, assim, como elemento essencial à institucionalização da educação (Lagares, 2007; 2014; 2015). E as conferências podem ser instrumentos de gestão democrática nos Sistemas de Ensino/Educação, oportunizando a participação dos diversos atores educacionais na elaboração, monitoramento e avaliação dessa política pública nos estados e municípios do nosso país.

Da Conae, resultou a elaboração, pelo executivo nacional, do Projeto de Lei de PNE $n^{0}$ 8.035/2010, que, segundo Oliveira et al. (2011, p. 483), a despeito da constituição de uma rede de discussão em âmbito nacional, os "avanços contidos no documento final da Conae, resultado dos debates e disputas internas ocorridos no espaço democrático de discussão que esta possibilitou, não foram, em sua maioria, contemplados no PL n. 8.035/2010”. Entre os anos de 2012 e 2014, o PL $n^{\circ}$ 8.035/2010 tramitou no Senado e retornou à Câmara dos Deputados, sendo aprovado em 03 de junho de 2014 e sancionado sem vetos pela Presidente Dilma Roussef em 25 de junho deste ano, transformando-se na Lei $n^{0}$ 13.005/2014, que aprovou o PNE para o próximo decênio seguinte.

No ano de 2014 aconteceu a II Conae, prevista para o mês de fevereiro, mas realizada no período de 19 a 23 de novembro, em Brasília, discutindo o tema “O PNE na Articulação do Sistema Nacional de Educação: Participação Popular, Cooperação Federativa e Regime de Colaboração". Seu objetivo, inicialmente, seria voltado ao planejamento da educação, sendo o de avaliar a execução do PNE, uma disposição do PL de PNE. Contudo, com a aprovação do PNE apenas em junho de 2014, ainda não havia o que avaliar de sua implantação, e o Fórum Nacional de Educação, órgão responsável pela organização do evento, definiu outro objetivo geral, o de "propor a Política Nacional de Educação, indicando responsabilidades, corresponsabilidades, 
atribuições concorrentes, complementares e colaborativas entre os entes federados e os sistemas de ensino".

Para Dourado (2014, p. 9), a Conae teve um importante papel político, pois:

... ao problematizar a necessidade do estabelecimento de diretrizes para a instituição de um sistema nacional de educação que possibilite a ação articulada entre os entes federados, a efetivação de planejamento sistemático, que, após avaliar o conjunto de ações, programas e planos em desenvolvimento, contribua para o estabelecimento de políticas de Estado, programas e ações que garantam organicidade entre as políticas educacionais no país, envolvendo os diferentes órgãos de gestão educacional (MEC, sistemas de ensino e instituições) e, ainda, destacando a necessária mediação entre o Estado, demandas sociais e o setor produtivo, de modo a se avançar na superação do cenário educacional, historicamente demarcado pela fragmentação ou superposição de ações e programas, pela centralização das políticas de organização e gestão da educação básica no país.

Os eixos temáticos de discussão do evento se articularam com a temática central da Conferência, problematizando questões educacionais, como Sistema Nacional de Educação, diversidade, planejamento, federalismo e participação popular na elaboração das políticas educacionais. Com as alterações, a II Conae deixou de ser um evento exclusivamente voltado para 0 planejamento da educação nacional, transformado este tema em um de seus objetivos específicos.

Em 2016, com o golpe de estado contra a Presidenta Dilma Roussef, Michel Temer assumiu a presidência do país, e provocou diversas reformas que desmantelaram estruturas democráticas já consolidadas e usurparam vários direitos sociais conquistados nas últimas décadas, afetando as realizações das conferências de educação.

A Portaria $n^{\circ} 577 / 17$, antecedida pelo Decreto do Executivo de 27 de abril de 2017, que realizou uma nova convocação para a III Conferência Nacional de Educação, desrespeitou as deliberações do Plano do Fórum Nacional de Educação (FNE) com relação ao cronograma da Conae 2018, subordinando o FNE ao Ministério da Educação (MEC) na condução do evento, o que contrariava o artigo $6^{\circ}$ da Lei $n^{\circ} 13.005 / 2014$.

Naquele contexto, as entidades e movimentos sociais do campo educacional anunciaram que não participariam mais do Fórum Nacional de Educação, desfigurado pelo governo Michel Temer e protagonizaram uma saída coletiva e posteriormente divulgaram a constituição do Fórum Nacional Popular de Educação (FNPE) e a construção da Conferência Nacional Popular de Educação (Conape) para 2018. 
De acordo com Oliveira e Süssekind (2019, p. 2), a Conape realizada em 2018, em lugar da Conae, apresentou como uma ação de resistência na defesa da educação pública, com a produção de documentos, publicações e orientações para organização de conferências subnacionais.

... foi uma ação importante na resistência, também presente em outros tantos eventos, documentos e publicações. Tendo como um de seus objetivos avaliar os processos de implantação do PNE 2014-2024, em risco desde o golpe de 2016, a Conferência também foi voltada à efetivação de debates sobre o que vem sendo feito por governos locais, movimentos sociais e educadores de todo o país, como resistência e como proposição, nos processos de implantação do PNE, com questionamentos também em relação a algumas de suas metas e à sua implementação (Oliveira \& Süssekind, 2019, p. 2).

É nesta perspectiva que entendemos as conferências municipais, como espaços importantes de construção da resistência e da mobilização pela democracia.

\section{Conferências Municipais de Educação: questões teóricas e legais}

O Plano Nacional de Educação de 2014, por meio de seu art. $6^{\circ}$, possibilitou o país que contasse com a disposição legal das conferências educacionais como um dos elementos dos sistemas de educação e ensino:
Art. 6 - A União promoverá a realização de pelo menos 2 (duas) conferências nacionais de educação até o final do decênio, precedidas de conferências distrital, municipais e estaduais, articuladas e coordenadas pelo Fórum Nacional de Educação, instituído nesta Lei, no âmbito do Ministério da Educação.

II - promoverá a articulação das conferências nacionais de educação com as conferências regionais, estaduais e municipais que as precederem.

$\S 2^{\underline{0}}$ As conferências nacionais de educação realizar-se-ão com intervalo de até 4 (quatro) anos entre elas, com o objetivo de avaliar a execução deste PNE e subsidiar a elaboração do plano nacional de educação para o decênio subsequente.

...

Meta 19: Assegurar condições, no prazo de 2 (dois) anos, para a efetivação da gestão democrática da educação, associada a critérios técnicos de mérito e desempenho e à consulta pública à comunidade escolar, no âmbito das escolas públicas, prevendo recursos e apoio técnico da União para tanto.

19.3) incentivar os Estados, o Distrito Federal e os Municípios a constituírem Fóruns Permanentes de Educação, com o intuito de coordenar as conferências municipais, estaduais e distrital bem como efetuar o acompanhamento da execução deste PNE e dos seus planos de educação (grifos nossos) (Brasil, 2014).

Na Meta 19 e na Estratégia 19.3 (Lei $n^{\circ}$ 9.394, de 20 de dezembro de 1996), que trata das conferências como mecanismo da gestão democrática, a ideia parece ser, então, que as conferências sejam espaços 
sociais de discussão, utilizados como instrumento para o planejamento da educação nos Sistemas Municipais de Ensino. Nessas circunstâncias, os estados, os municípios e o Distrito Federal deverão organizar suas conferências.

A partir de meados dos anos de 2010, no Brasil e no estado do Tocantins, vários municípios adotaram as conferências como estratégia de mobilização no processo de planejamento da educação na elaboração dos seus planos municipais de educação. Entretanto, estas podem apresentar concepções distintas, a depender das perspectivas teóricas e políticas e objetivos que seus organizadores utilizam para organizar e embasar tais eventos.

Neste trabalho, tem-se por conferências municipais de educação o conceito definido por Santos (2008), que as define como espaços de correlações de forças, com limitações, oportunidades e desafios. São espaços fomentadores de mudanças na gestão pública e de instituição de novas relações entre governo e sociedade civil, constituindo, ainda, um mecanismo de gestão democrática com possibilidades de contribuir para 0 planejamento da política educacional no município.

Apresentando propostas às instituições públicas e ao parlamento a respeito do que queremos para a educação brasileira, Dourado (2018, p. 223) reforça que as conferências também podem contribuir para a participação social na avaliação da política pública, fortalecendo a gestão democrática:

As conferências, especialmente nos últimos anos, ganharam especial importância para configuração de novas relações, mais democráticas, entre o Governo e a sociedade civil em geral, sendo institucionalizadas. Vinham se consolidando no ciclo das políticas públicas como instrumentos de aperfeiçoamento, monitoramento, produção de novos conteúdos e efetivo envolvimento de diversos atores na definição dos rumos das políticas, com a ampliação da participação e escuta da sociedade, nos mais diversos níveis.

Destacamos que o planejamento, organização e realização de conferências municipais de educação, nesse momento atual da educação brasileira, e do estado do Tocantins em particular, podem servir de espaços e mecanismos de resistência em relação ao esvaziamento e desmonte da educação pública, levando o que se tem feito pelo atual governo federal, de orientação fascista e práticas autoritárias, visando à satisfação do princípio da gestão democrática do ensino público.

No segundo semestre de 2021, os municípios tocantinenses estão em processo de encaminhamento operacional para planejamento, organização e divulgação, com vistas à realização das suas Conferências de Educação, todas sob 
a organização do Fórum Permanente de Educação Municipal ou Comissão Especial, sendo instrumentos da gestão democrática e elementos do processo de institucionalização efetiva dos Sistemas Municipais de Ensino/Educação.

Isso é particularmente importante porque o campo da educação é caracterizado como um espaço de disputa de projetos, tendo, por um lado sujeitos, entidades e movimentos em defesa dos direitos garantidos na Constituição Federal (CF) de 1988, na Lei de Diretrizes e Bases da Educação de 1996 e na Lei do Plano Nacional de Educação de 2014, e, por outro, sujeitos e organizações com intencionalidades autoritárias, privatistas e de enfraquecimento das políticas públicas educacionais.

Um bom exemplo de materialidade dessa concepção distinta sobre pensar e fazer educação ocorre em alguns municípios do Estado do Tocantins que assumem o papel de coadjuvantes no planejamento, definição e avaliação de suas políticas públicas educacionais ao se renderem aos assédios de fundações, institutos e consultorias privadas, que assumem o protagonismo na gestão da educação municipal, definindo o currículo escolar, a formação de professores e gestores e, em alguns casos, até o modelo de escola, caracterizando a privatização da educação pública municipal.

Em contraposição à essa tendência neoliberal, que contraria princípios constitucionais como a gestão democrática do ensino público e o pluralismo de ideias e concepções pedagógicas, na próxima seção apresentaremos o trabalho da Rede ColaborAção Tocantins (RCT), que surgiu em março de 2020, no contexto da pandemia, com o objetivo de apoiar as redes e sistemas municipais de ensino/educação no enfrentamento da crise educacional ocasionada pela Covid-19.

Demonstraremos que, ao contrário da perspectiva da iniciativa privada, a RCT defende como princípios o direito à educação com qualidade socialmente referenciada, a gestão democrática com participação direta, a autonomia municipal, o regime de colaboração público-público e a institucionalização efetiva dos sistemas municipais de ensino/educação, tendo como foco a democratização dos conhecimentos clássicos e da escola pública, universal, inclusiva, democrática, autônoma, com responsabilidade estatal na promoção da justiça social, de acordo com o disposto na Constituição Federal (CF/1988) (Brasil, 1988), na Lei de Diretrizes e Bases da Educação Nacional (LDB) - n 9.394 (Brasil, 1996) e no Plano Nacional de Educação (PNE) - Lei $n^{\circ}$ 
13.005 (Brasil, 2014). Para tanto, a RCT assume o compromisso de, em conjunto com as redes e sistemas municipais de educação, construir um plano de trabalho para a gestão da educação municipal, a partir das demandas, necessidades e especificidades dos municípios, promovendo a autonomia municipal e a emancipação dos profissionais da educação no âmbito dos municípios.

No cenário estabelecido, com projetos e ações estratégicas que evidenciam uma prática ultraliberal que agrava de modo sistemático os processos de planejamento e gestão participativa das políticas públicas educacionais, ao lado de iniciativas como as da RCT, o documento da Conape aparece como "uma luz no fim do túnel" de resistência em defesa da escola pública, com ideias e propostas em favor dos direitos garantidos na CF de 1988, na LDB e no PNE, da escola pública, universal, inclusiva, democrática, autônoma, com responsabilidade estatal na promoção da justiça social.

Esse movimento de resistência fica claro na escolha do tema da conferência, que é "Reconstruir o país: a retomada do Estado Democrático de direito e a defesa da educação pública e popular, com gestão pública, gratuita, democrática, laica, inclusiva e de qualidade social para todos/as" (Conape, p.7).

\section{A experiência da Rede Colaboração Tocantins}

No contexto inicial da pandemia da Covid-19, março de 2020, a Rede colaboração Tocantins (RCT) ${ }^{\mathrm{i}}$, constituída por instituições públicas presentes no Estado do Tocantins, assumiu o compromisso de apoiar as redes e sistemas municipais de educação no planejamento e gestão da educação municipal nesse contexto de enfrentamento da crise educacional ocasionada pela Covid-19.

No cenário estabelecido pela pandemia, a RCT optou por planejar e desenvolver suas atividades de formação, acompanhamento e avaliação considerando as demandas e especificidades da gestão em cada município, ou seja, exercitando a práxis que permite interpretar a realidade objetiva e refletir sobre ela, a fim de buscar no planejamento e na gestão participativa as respostas às suas necessidades educacionais.

No segundo semestre de 2021, em que os municípios tocantinenses estão em fase de planejamento, organização e realização das suas Conferências de Educação, no que se refere ao trabalho específico da formação de gestores educacionais da educação municipal (Bloco I de organização da Rede, que contempla como cursistas os dirigentes municipais de educação, presidente do 
CME, presidente do Conselho do Fundeb, coordenador do Fórum Municipal de Educação, técnicos das Secretarias Municipais de Educação, diretores e coordenadores pedagógicos e administrativos das escolas) a equipe da RCT planejou e desenvolveu atividades sempre pautadas em conteúdos relacionados aos elementos do Sistema Municipal de Ensino/Educação, notadamente, o Plano Municipal de Educação (PME) o Conselho Municipal de Educação (CME), Fórum Municipal de Educação (FME) e as Conferências Municipais de Educação, entre outros, a serem desenvolvidos durante os módulos realizados entre outubro de 2020 e novembro de 2021, tendo como referência o diagnóstico realizado em 2020.

Assim, nos meses de outubro e novembro de 2021 a Rede organizou o planejamento de suas atividades (nos módulos VI e VII) especificamente com o propósito de contribuir com a preparação e organização das Conferências Municipais de Educação, articulando-as sinergicamente com o Plano Municipal de Educação e com o Fórum Municipal de Educação, enquanto elementos essenciais para a efetiva institucionalização do SME tendo a concretização das metas e estratégias do Plano Municipal como referência e foco. Importa entender que esses elementos se interagem e se misturam para o cumprimento dos objetivos das Conferências.

No material do módulo VI, intitulado Processo de Institucionalização Efetiva de Sistemas Municipais de Ensino/Educação: FME, PME e Conferências Municipais de Educação (RCT, 2021), integrante da formação de gestores da educação municipal, realizado em 19 de outubro de 2021, aparece como objetivo geral:

Orientar o processo de institucionalização efetiva dos sistemas municipais de ensino/educação no Tocantins, a constituição da autonomia municipal e o cumprimento de incumbências no campo da educação, integrando-se às políticas e planos educacionais da União e dos Estados, combinando formação, acompanhamento, monitoramento e avaliação, abordando, em especial, as temáticas Fórum Permanente da Educação Municipal (FME), Plano Municipal de Educação (PME) e Conferência Municipal [Popular] de Educação (RCT, 2021, s/p) .

Entre os objetivos específicos trabalhados no referido módulo de formação, acompanhamento e avaliação, destacamos dois:

a) Discutir a respeito das relações necessárias entre o Fórum Permanente da Educação Municipal, os Planos de Educação Nacional, Estadual e Municipal e a Conferência Municipal de Educação, considerando que os Municípios devem refletir e se preparar para a realização das Conferências 
Municipais [Populares] de Educação.

b) Apresentar sugestões sobre a materialização das Conferências Municipais [Populares] de Educação (presenciais ou online): encaminhamentos operacionais para o planejamento, organização; divulgação e realização (regimento; abertura; palestras; relatores por eixos e na plenária final) garantindo a participação social e o monitoramento e avaliação do cumprimento dos planos de educação (RCT, 2021, s/p).

Nos módulos VI e VII, a equipe da Rede articulou, para além dos encontros formativos, reuniões com os cursistas visando o planejamento para orientações acerca da realização das Conferências Municipais [Populares] de Educação e suas relações com o Fórum Permanente da Educação Municipal, os Planos de Educação Nacional, Estadual e Municipal.

No módulo VII, com a temática "Painel Articulado: Sistema Municipal de Educação: o lugar do PME, do Fórum Permanente de Educação Municipal e a Conferência Municipal de Educação", a equipe RCT definiu dois objetivos para o encontro síncrono de formação:

a) Discutir o processo de institucionalização efetiva dos sistemas municipais de ensino/educação no Tocantins, a constituição da autonomia municipal e o cumprimento de incumbências no campo da educação, integrando-se às políticas e planos educacionais da União e dos Estados, combinando formação, acompanhamento, monitoramento e avaliação. b) Discutir Metodologia para a realização da Conferência Municipal de Educação articulada ao Sistema Municipal de Educação/Ensino tendo o Plano Municipal de Educação como referência e foco, considerando a Lei $n^{\circ} 13.005$, de 25 de junho de 2014, que aprova o Plano Nacional de Educação (PNE). (RCT, 2021, $\mathrm{s} / \mathrm{p})$.

Nesse módulo formativo o conteúdo programático aborda: a) o processo de institucionalização efetiva dos sistemas municipais de ensino/educação; b) autonomia municipal; e Conferência Municipal de Educação, articulada ao Plano Municipal de Educação como referência e foco, considerando a Lei $\mathrm{n}^{\circ}$ 13.005, de 25 de junho de 2014, que aprova o Plano Nacional de Educação (PNE).

A análise a respeito do trabalho de formação desenvolvido pela equipe da Rede ColaborAção Tocantins, especialmente no Bloco I - Formação da Gestão da Educação Municipal, sobre os elementos que constituem (e são fundamentais para) a institucionalização efetiva dos sistemas municipais de ensino/educação em municípios do Estado do Tocantins (Lagares, 2008), aponta para o firme propósito de defesa do direito à educação e da educação pública e popular, com gestão pública, gratuita, democrática, laica, inclusiva e de qualidade social para todos, tendo o PNE como epicentro das 
políticas públicas educacionais. Nessa perspectiva, a formação, acompanhamento praxiológico e avaliação contínuos partem do reconhecimento da importância da sinergia que deve existir entre os elementos do sistema, tomando a realidade da educação municipal como ponto de partida e ponto de chegada, considerando o contexto estadual e nacional, a partir da consonância e alinhamento entre os planos de educação dos respectivos entes federados, com vistas a contribuir, efetivamente, para o processo de gestão e desenvolvimento da educação municipal (RCT, 2021).

\section{Considerações finais}

O presente artigo teve como objetivo compreender as Conferências Municipais de Educação como elementos do Sistema Municipal de Educação e como espaços de materialização do princípio da gestão democrática da educação, tendo o Plano Municipal de Educação como referência e foco.

Destacamos que o planejamento, organização e realização de Conferências Municipais de Educação, nesse momento atual da educação brasileira, e do Estado do Tocantins em particular, pode servir de espaço e mecanismo de resistência em relação ao esvaziamento e desmonte da educação pública, visando a satisfação dos princípios do direito à educação, da gestão democrática do ensino público e da autonomia municipal, garantidos na CF de 1988 e recepcionados pela LDB 9394/96.

Assim, entendemos que as Conferências são espaços essenciais de reivindicação, proposição e de avaliação das políticas públicas educacionais, não apenas como simples legitimadoras das mesmas, uma vez que a participação popular nas Conferências tem sido uma conquista e um significativo avanço para o campo educacional. Por outro lado, este é um processo ainda incipiente e tímido no seu potencial, pois no Brasil ainda precisamos da firme adesão da sociedade civil e política na concepção, organização e implementação destes espaços.

Visando a mediação dos aspectos relacionados à práxis educacional em municípios do Estado do Tocantins, apresentamos a experiência do trabalho de formação, acompanhamento praxiológico e avaliação desenvolvido pela Rede ColaborAção Tocantins, especialmente, no tocante ao processo de institucionalização efetiva de sistemas municipais de ensino/educação, no âmbito do Estado, a partir da articulação sinérgica que envolve planejamento, organização e realização das conferências municipais de educação, tendo o Plano Municipal como referência e 
foco, com vistas ao processo de gestão e desenvolvimento da educação municipal.

\section{Referências}

Chagas, F. (2010). A Conferência Nacional de Educação (Conae) e o Plano Nacional de Educação (PNE). Educação $e$ Sociedade, 31(112), 1031-1058. https://doi.org/10.1590/S0101$\underline{73302010000300019}$

Conferência Nacional de Educação (Conae). (2010) Construindo o sistema nacional articulado de educação: o Plano Nacional de Educação, diretrizes e estratégias de ação. Documento final da Conae 2010. Brasília, DF: MEC. Recuperado de: http://Conae.mec.gov.br/images/stories/pdf /pdf/documetos/documento_final.pdf.

Conferência Nacional de Educação (Conae). (2011). Anais da Conferência Nacional de Educação: CONAE 2010: Construindo o Sistema Nacional Articulado de Educação: o Plano Nacional de Educação, diretrizes e estratégias de ação (volume I). Brasília, DF: Ministério da Educação.

Conferência Nacional Popular de Educação (Conape). (2018). Documento final. Plano de Lutas. CONAPE 2018. Recuperado de: https://fnpe.com.br/docs/documentos/docsconferencia/fnpe-conape2018-documentofinal-planodelutas.pdf.

Conferência Nacional Popular de Educação (Conape). (2021). Orientações rumo à Conape. Recuperado de: https://www.educacao.ma.gov.br/files/202 1/06/Orienta\%C3\%A7\%C3\%B5es-Rumo\%C3\%A0-CONAPE-2022_FINAL.pdf.

Constituição da República Federativa do Brasil. (1988, 05 de outubro). Recuperado de:

http://www.planalto.gov.br/ccivil_03/const ituicao/constituicao.htm.

Creswell, J. W. (2010). Projeto de Pesquisa: métodos qualitativo, quantitativo e misto. Porto Alegre: Artmed, 2010.

Dourado, L. F. (2014). Plano Nacional de Educação, Conferência Nacional de Educação e a construção do Sistema Nacional de Educação: dilemas e proposições. Jornal de Políticas Educacionais, 16, 1-3. https://doi.org/10.5380/jpe.v8i16.40307

Gouveia, A. B. (2010). A Conferência Nacional de Educação 2010: Participação e deliberação em novas arenas de disputa. Educere et Educare - Revista de Educação, 5(10), 1-16.

Lagares, R. (2007). Organização da educação municipal no Tocantins: entre a conservação de redes e o processo de institucionalização efetiva de sistemas (Tese Doutorado). Universidade Federal de Goiás, Goiás.

Lagares, R. (2014). Arranjos para os municípios no campo das políticas públicas e gestão educacional. Desafios: Revista Interdisciplinar da Universidade Federal do Tocantins, 1(1), 93-113. https://doi.org/10.20873/uft.2359$\underline{3652.2014 \mathrm{v} 1 \mathrm{n} 1 \mathrm{p} 95}$

Lagares, R. (2015). Institucionalização de sistemas municipais de educação: concepções e complexidade. Roteiro, 40(1), 149-168.

https://doi.org/10.18593/r.v40i1.4268

Lagares, R. et al. (2020a). Gestão da educação: validação das ações administrativas e pedagógico-curriculares e finalização do ano letivo de 2020. Palmas: UFT/Proex. 
Lagares, R. et al. (2020b). Gestão da educação na conjuntura da pandemia Com a palavra, cursistas e formadores. Palmas: UFT/Proex.

Lagares, R. et al. (2021). Gestão das Redes $e$ dos Sistemas Educacionais: afirmação dos direitos à vida e à educação no retorno às atividades escolares em 2021. Palmas: UFT/Proex.

Lei $\mathrm{n}^{\circ}$ 9.394, de 20 de dezembro de 1996. (1996, 20 de dezembro). Estabelece as Diretrizes e Bases da Educação Nacional. Recuperado de: http://www.planalto.gov.br/ccivil_03/leis/1 9394.htm.

Lei $\mathrm{n}^{0}$ 13.005, de 25 de junho de 2014. (2014, 25 de junho). Aprova o Plano Nacional de Educação - PNE e dá outras providências. Recuperado de: http://www.planalto.gov.br/ccivil_03/_ato2 011-2014/2014/lei/113005.htm.

Oliveira et al. (2011). Por um Plano Nacional de Educação (2011-2020) como política de Estado. Revista Brasileira de Educação 16(47), 483-492.

Oliveira, I. B., \& Süssekind, M. L. T. (2019). Conservador e Resistência: a Conape em defesa da educação pública. Educação \& Realidade, 44(3). e84868. https://doi.org/10.1590/2175-623684868

Portaria n. ${ }^{\circ}$ 577, de 27 de abril de 2017. (2017, 27 de abril). Recuperado de: https://www.in.gov.br/materia//asset_publisher/Kujrw0TZC2Mb/content/i d/20184519/do1-2017-04-28-portaria-n577-de-27-de-abril-de-201720184461\#: :text=Disp\%C3\%B5e\%20sob re\%20o\%20F\%C3\%B3rum\%20Nacional\% 20de\%20Educa\%C3\%A7\%C3\%A3o.\&text =XXXIV\%20\%2D\%20representa\%C3\%A 7\%C3\%A3o\%20do\%20Sistema\%20\%22S, dos\%20respectivos\%20\%C3\%B3rg\%C3\% A3os\%20e\%20entidades.
Projeto de Lei n. 8.035, de 20 de dezembro de 2010. (2010, 20 de dezembro). Aprova o Plano Nacional de Educação para o decênio 2011-2020 e dá outras providências. Recuperado de: http://portal.mec.gov.br/index.php?option= com_docman\&view=download\&alias=71.

Santos, C. M. V. (2008) Conferência Municipal de Educação (COMUDE) e a Política Educacional no Município de Recife, no período de 2002 a 2006. 2008 (Dissertação de Mestrado). Universidade Federal de Pernambuco, Recife.

Santos, L. V. (2019). Privatizações na Educação Básica no Tocantins: Parcerias Público-Privadas $X \quad$ Regime de Colaboração Público-Público. (Dissertação de Mestrado). Universidade Federal do Tocantins, Palmas. http://hdl.handle.net/11612/1455

Saviani, D. (1999). Sistemas de ensino e planos de educação: o âmbito dos municípios. Educação \& Sociedade, 69, 119-136. https://doi.org/10.1590/S0101$\underline{73301999000400006}$

\footnotetext{
A Rede ColaborAção Tocantins (RCT) foi articulada pela União Nacional dos Dirigentes Municipais de Educação do Tocantins (seccional Tocantins), Ministério Público do Estado do Tocantins e especialistas em educação municipal do Grupo de Estudo, Pesquisa e Extensão em Educação Municipal (GepeEM) da Universidade Federal do Tocantins, coordenado pela Prof ${ }^{a}$ Dra. Rosilene Lagares, tendo como referência o regime de colaboração público-público defendido por Santos (2019), com o objetivo de apoiar as redes e sistemas municipais de ensino/educação no enfrentamento da crise educacional ocasionada pela Covid-19.
} 


\section{Informações do Artigo / Article Information}

Recebido em : 13/11/2021

Aprovado em: 04/12/2021

Publicado em: 19/12/2021

Received on November 13th, 2021

Accepted on December 04th, 2021

Published on December, 19th, 2021

Contribuições no Artigo: Os(as) autores(as) foram os(as) responsáveis por todas as etapas e resultados da pesquisa, a saber: elaboração, análise e interpretação dos dados; escrita e revisão do conteúdo do manuscrito e; aprovação da versão final publicada.

Author Contributions: The author were responsible for the designing, delineating, analyzing and interpreting the data, production of the manuscript, critical revision of the content and approval of the final version published.

Conflitos de Interesse: Os(as) autores(as) declararam não haver nenhum conflito de interesse referente a este artigo.

Conflict of Interest: None reported.

\section{Avaliação do artigo \\ Artigo avaliado por pares.}

\section{Article Peer Review}

Double review.

\section{Agência de Fomento}

Não tem.

\section{Funding}

No funding.

\section{Como citar este artigo / How to cite this article}

APA

Almeida, G. Q. M., Damasceno, A., \& Santos, L. V. (2021). A gestão democrática nos sistemas de ensino: a experiência das Conferências Municipais de Educação e da Rede de Colaboração Tocantins no século XXI. Rev.
Bras.
Educ.
Camp., 6
e13424.

http://dx.doi.org/10.20873/uft.rbec.e13424

ABNT

ALMEIDA, G. Q. M.; DAMASCENO, A.; SANTOS, L. V. A gestão democrática nos sistemas de ensino: a experiência das Conferências Municipais de Educação e da Rede de Colaboração Tocantins no século XXI. Rev. Bras. Educ. Camp., Tocantinópolis, v. 6, e13424, 2021. http://dx.doi.org/10.20873/uft.rbec.e13424 